\title{
Abrasion process between a fibre mooring line and a corroded steel element during the transit and commissioning of a Marine Renewable Energy device
}

\author{
Manuel Herduin ${ }^{\mathrm{a}}$, Stephen Banfield ${ }^{\mathrm{b}}$, Sam D. Weller ${ }^{\mathrm{a}}$, Philipp R. Thies ${ }^{\mathrm{a}}$, and Lars Johanning ${ }^{\mathrm{a}}$ \\ ${ }^{\text {a }}$ CEMPS College of Engineering, Mathematics and Physical Science, Renewable Energy Research Group, University of Exeter, Penryn Campus, Treliever Rd, Penryn TR10 9EZ, UK \\ ${ }^{\mathrm{b}}$ Tension Technology International Ltd,69 Parkway, Eastbourne, Sussex, BN20 9DZ, UK
}

\section{ARTICLE INFO}

\section{Article history:}

Received

Received in revised form

Accepted

Available online

\section{Keywords:}

Abrasion

Polyester rope

MRE commissioning

Sea trial

OrcaFlex

\section{ABSTRACT}

The interaction between fibre rope and steel parts on vessels (fairlead and roller) is technically well understood but not commonly published in codes or practised by mariners. What appears to be a smooth steel surface to the naked eye can still be abrasive medium to synthetic mooring components. There are very few reports of external rope abrasion tests in the literature. The surface finish at the contact between the rope and the steel guide can cause damage and consequently prematurely degrade the exposed yarns of the rope and thus reduce the overall load bearing capacity of the rope.

The standard ISO 18692 [1] recommends that prolonged cycling of a rope around rollers should be avoided, however it is specified that occasional bending and running over rollers is allowable. There are two guides to specify surface roughness. MEG 3 [2] states that steel fairleads should be polished to Ra10, but in practice this may be difficult to achieve or obtain with carbon steel. The US Navy guide also states that the surface of steel should have better than $125 \mu$ i or $3.2 \mathrm{Ra}[3]$.

The study presented here discusses the bending of a synthetic rope around a roller during transportation. It relates the motion behaviour of the vessel to rope wear and provides a detailed numerical simulation correlated with post analysis of the rope after the failure. The investigations show that the roughness of the steel roller caused the abrasion of the rope which was exacerbated through the vessel dynamics, resulting in the rope having an estimated residual strength of $14 \%$ MBL before rupture. The experimental tests have established a linear relation between strength loss and surface roughness and it was observed that the abrasion mainly occurs in the early stages of load cycling. The presented work recommends the use of lubricated nylon instead of carbon steel rollers to limit abrasive rope wear. The paper also devises a methodology to carefully assess and quantify potential rope abrasion to ensure that the residual rope strength withstands the required load capacity.

\section{Summary}

This paper brings together two experiences from TTI (Tension Technology International) and the UoE (University of Exeter) and aims to quantify the damage that could be experienced by fibre mooring lines during the transit and commissioning phase of Marine Renewable Energy (MRE) devices.

1. While deploying a new prototype of anchoring system for a MRE device, UoE experienced the failure of a new polyester mooring line during transit to site (90 minute duration). A thorough visual inspection supported by Scanning Electron Macroscopy (SEM) analysis and tensile test have established the physical conditions of the fibre rope before its failure.

2. Wear testing led by TTI has investigated and established a relation between the degree of abrasion sustained and the residual strength of Dyneema ${ }^{\circledR}$ fibre ropes. The ropes were submitted to friction forces via cycling over a roller and a fairlead with different abrasive surfaces (from 7.6 to $254.3 \mu \mathrm{m})$. Negligible wear occurred with the low roughness surfaces and very high wear at the higher roughness surfaces.

The load experienced by the polyester line during the deployment of the anchoring system was simulated with the software OrcaFlex ${ }^{\mathrm{TM}}$. Dynamic modelling using representative conditions indicates that the polyester mooring line was loaded between 3 and $20 \%$ of its Minimum Breaking Load (MBL) which is well below the design load of the rope.

\section{Introduction}

To date there are only a few MRE designs which have achieved a pre-commercial development status. Experience in deploying such devices and specific guidance are missing. The approach of designers is thus conservative and based on the offshore oil and gas industry and anecdotal evidence [4].

The use of synthetic fibre ropes for mooring systems has seen a sudden rise in marine applications over the last two decades [5] albeit mainly for deep water mooring [6]. Experience and feedback from the use of polyester ropes for MRE device moorings is still limited in terms of publications produced.

This paper focuses on the commissioning phases of MRE devices, with a specific focus on the deployment of a novel anchoring system. Handling, lifting and rigging of mooring lines could result in damage during transport or installation as discussed in [7] and [8]. The strength of a rope will inevitably degrade from mishandling. Several research programs have been carried out to investigate the abrasion and twisting damage by rope manufacturers for towing systems. For example incorrect handling during transport could cause significant damage to the rope due to abrasion and the application of sudden high loads is one of the most severe conditions that a rope can experience [9].

Certification standards and specific test methods have been developed to test the abrasion resistance of yarns [10] - [11]. The abrasion mechanism was described in [12] as a sequence of fibre peeling induced by surface shear forces. However the abrasion resistance of a fibre rope is not determined by standards and knowledge is only based on empirical test data.

The external abrasion resistance of a fibre rope is a function of multiple properties [13]:

- The rope construction (double braided, plaited, etc.) 
- The fibre materials (aramid, nylon, polyester, HPME, etc.)

- Fibre and rope lubricants and abrasion protection coatings

- Wet and dry conditions

- The tension in the rope and pressure on the abrasive surface

- The speed of the sliding over the surface

A better understanding of the abrasion effects on the strength loss can potentially reduce performance uncertainties and limit the normal wear damage experienced by MRE mooring components.

\section{Fibre rope observation}

\subsection{Background}

The present case study relates the abrasion of a polyester mooring line during the commissioning of a novel type of anchoring system in Falmouth Bay (UK) 1.25 miles away from the coast. The 28 tonnes anchoring system was connected to the deck winch of a multi-cat vessel and hung over the bow roller (made of steel) by a $48 \mathrm{~mm}$ diameter polyester line (12 strand plaited - $473 \mathrm{kN}$ MBL - 15m length) in a dual-line configuration as shown in Figure 1. The polyester rope was in wet conditions but the effect of the rope moisture was not considered in this research work. A wet Polyester rope is slightly less subjected to friction forces than a dry Polyester rope. As a result a lower rate of abrasion is likely to be observed on wet Polyester rope.

The presented study is structured in such a way to answer to the following questions:

- What were the loads experienced by the rope during the transit to the site?

- Did lateral sliding of the rope on the roller induce enough friction force to cause abrasion?

- Did axial stretching of the rope resulting from the dynamic response of the anchor and the vessel generate peak load magnitudes which exceeded the MBL of the rope?

- Would a smoother roller surface have prevented failure?

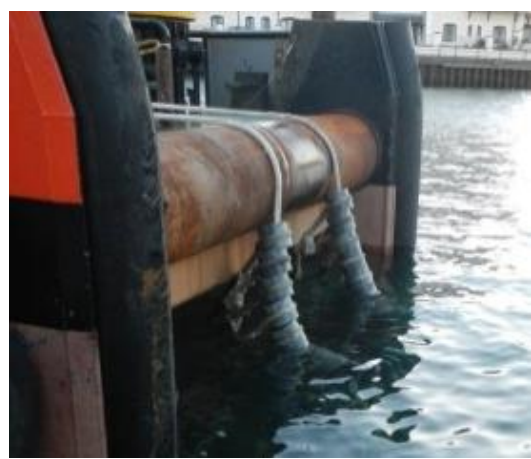

Figure 1. Anchoring system over the roller when connected to the vessel winch

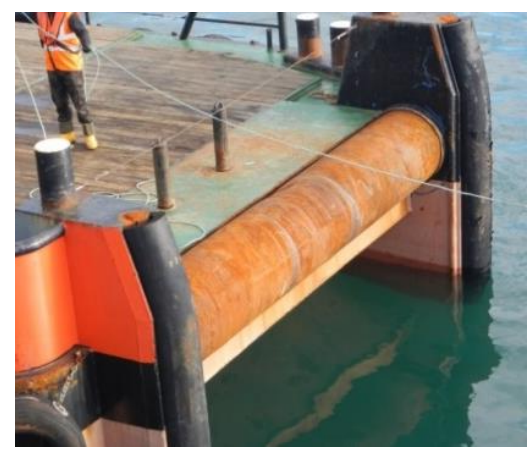

Figure 2. Roller after the operation: Polished marks are visible indicating friction between the roller and polyester rope

\subsection{Visual examination of the failed rope}

This section describes the visual inspection of the damaged polyester line. During the field trial, it is unlikely that the line was fully saturated during commissioning; instead there may have been some wetting due to sea spray. Since the line was used in a double-line configuration over the roller, two damaged sections were observed on the line.

The first damaged section is shown in Figure 3 at $5.5 \mathrm{~m}$ over 14 plaits. Although the steel roller of the vessel appeared smooth, seven strands were worn through. Rust contamination (caused by the rope sliding over the roller, Figure 2) can be observed by the discolouration in Figure 3.

The second damaged section is shown in Figure 4 at $10.8 \mathrm{~m}$ where most strand ends failed at the same location. Wear damage was sustained over 12 plaits, thus affecting every strand in the rope, with evidence of the fibres being heated. Localised melting resulting from friction is visible in small quantities at the failed section.

This minor surface heating produced by the low load range (< $20 \%$ MBL, as demonstrated later in the paper) is not significant because Polyester fibre ropes are classified as heat-resistant. Polyester is very insulating the surface heating and it would not penetrate far into the rope. It is thus considered that the rise of the steel roller temperature did not affect the rope's properties under these load conditions. This is a common case when a rope slides over a steel surface cylinder while under tension. The relationship between the rope diameter $d$ as it is bent around the drum steel diameter $D$ is expressed as a $D / d$ ratio. Ropemakers generally recommend the ratio $D / d=20 \%$ as safe working limit. The D/d ratio for the failed rope-roller system was $25 \%$, thus within the limit.

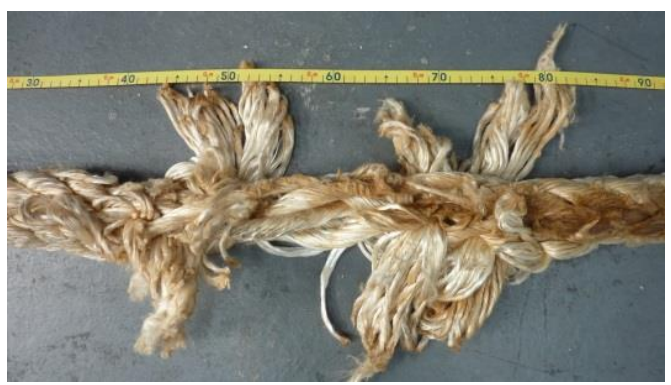

Figure 3. Damaged line at $5.5 \mathrm{~m}$

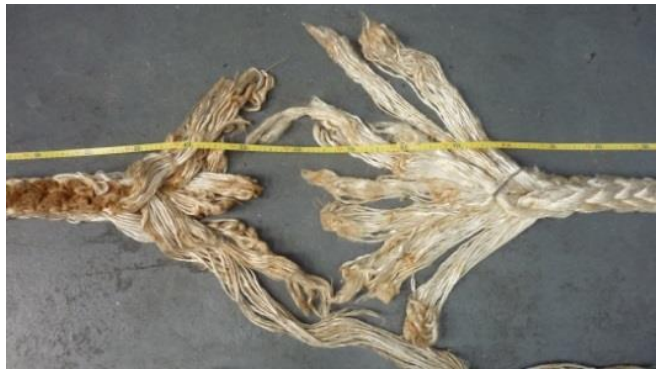

Figure 4. Damaged line at $10.8 \mathrm{~m}$

\subsection{Scanning Electron Macroscopy}

SEM was used to identify the cause of fibre damage. Most of the yarns presented evidences of abrasion damage. Fibre fracture and fibre peeling can be observed on Figure 5 A and B respectively. These damages are typical of situations where the fibres are heated by friction forces. 
However, a few SEM fibre specimens were observed to be distorted as shown in Figure $5 \mathrm{C}$. This could be the effect of the heat or the high contact pressure.

It is also observed that no yarns presented a stable crack propagation which excludes the possibility of low cycle fatigue damage.
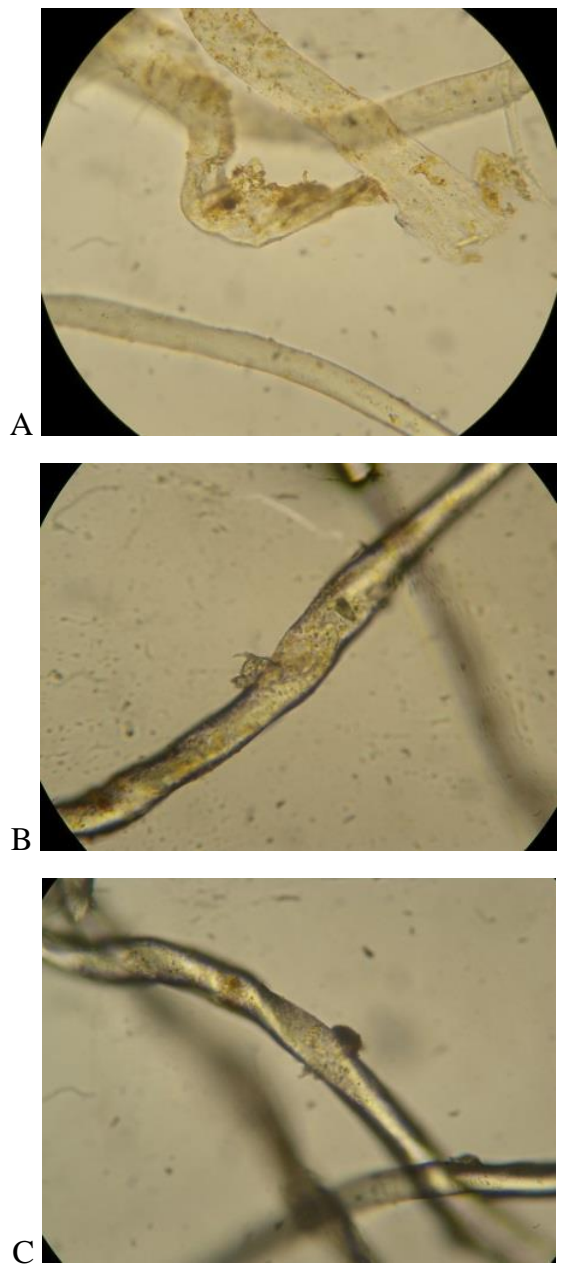

Figure 5. SEM micrographs of damaged yarns

\subsection{Yarn tensile tests}

The residual strength was calculated using Eq. 1 from [14]. The mean yarn breaking load is calculated for two strands (one outer and one inner) and then multiplied by the number of strands. This calculation is repeated at three different sections on the failed rope (i) non-damaged area (ii) abraded area (iii) failed area).

$$
\left[\mathrm{RF} * \sum_{\text {strand }=1}^{12}\left(\mathrm{YBL}_{M E A N} * \text { Strand }\right)\right] / \mathrm{MBL}_{\text {MEASURED }}
$$

Where:

$\begin{array}{ll}\text { RF } & \text { Realisation Factor } \\ \text { YBL }_{\text {MEAN }} & \text { Mean Yarn Breaking Load }(\mathrm{kN}) \\ \text { Strand } & \text { Number of strands at the section } \\ \text { MBL }_{\text {MEASURED }} & \text { Measured Minimum Breaking Load }(\mathrm{kN})\end{array}$

The Realisation Factor (RF) is dependent upon rope construction, rope manufacturer, and the type of fibre used. RF can be estimated theoretically with Eq.2 from [14].

$$
\mathrm{RF}=\mathrm{IYBL} / \mathrm{w} / \mathrm{MBL} / \mathrm{W}
$$

\begin{tabular}{|c|c|c|c|c|}
\hline & & $\begin{array}{l}\text { Mean yarn } \\
\text { breaking load } \\
(\mathrm{kN})\end{array}$ & Rope construction & $\begin{array}{l}\text { Total } \\
\text { breaking load } \\
(\mathrm{kN})\end{array}$ \\
\hline \multirow{5}{*}{ 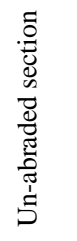 } & \multirow{4}{*}{$\begin{array}{l}\text { Outer } \\
\text { yarn } \\
\text { Inner } \\
\text { yarn }\end{array}$} & \multirow{2}{*}{2.572} & 13 yarns & \multirow{2}{*}{401} \\
\hline & & & 12 strands & \\
\hline & & \multirow{2}{*}{3.089} & 13 yarns & \multirow{2}{*}{482} \\
\hline & & & 12 strands & \\
\hline & & & Residual strength & $92 \% \mathrm{MBL}$ \\
\hline \multirow{5}{*}{ 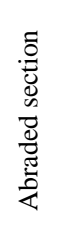 } & Outer & 1389 & 13 yarns & \multirow{2}{*}{217} \\
\hline & yarn & 1.509 & 12 strands & \\
\hline & Inner & 2761 & 13 yarns & 431 \\
\hline & yarn & 2.101 & 12 strands & 401 \\
\hline & & & Residual strength & $68 \% \mathrm{MBL}$ \\
\hline \multirow{3}{*}{ 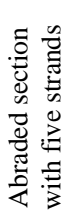 } & $\begin{array}{l}\text { Outer } \\
\text { yarn }\end{array}$ & 0.698 & 27 yarns & 18.4 \\
\hline & $\begin{array}{l}\text { Inner } \\
\text { yarn }\end{array}$ & 2.154 & 53 yarns & 115 \\
\hline & & & Residual strength & $14 \% \mathrm{MBL}$ \\
\hline
\end{tabular}

\section{Table 1}

Results of the yarn tensile tests

Where:

$\begin{array}{ll}\text { IYBL } & \text { Individual Yarn Breaking Load }(\mathrm{kN}) \\ \mathrm{w} & \text { Yarn weight }(\mathrm{g} / \mathrm{m}) \\ \mathrm{MBL} & \text { Rope Minimum Breaking Load }(\mathrm{kN}) \\ \mathrm{W} & \text { Rope weight }(\mathrm{g} / \mathrm{m})\end{array}$

However, the RF can also be found by yarn testing on a new fibre rope with Eq. 1. For this case study the RF was found to be 0.495. Results from the tests are listed in Table 1.

The outer yarn breaking load was slightly lower than the inner yarn breaking load due to some minor surface abrasion. The rope residual strength was found to be $92 \% \mathrm{MBL}$ for the un-abraded section and $68 \% \mathrm{MBL}$ for the abraded section adjacent to the failure. Outside the damaged area of the line, the tensile strength of the rope is still within limits of usability.

The same calculation was performed for the section presented in Figure 4 where five strands remained on the rope. This section is the other leg of the drawstring that was equally loaded and abraded and thus best represents the residual strength at the time of the failure in the other leg. For this section the residual strength was found to be $14 \% \mathrm{MBL}$. The numerical model detailed later in this paper indicated that the simulated load was greater than the measured residual strength.

\section{Indicative abrasion testing programs}

The rope failure investigated in the previous section has raised a concern about the possible influence of rough surface element on fibre rope. With this in mind this section presents test data from a previously conducted, unpublished wear testing program carried out to estimate the performance of Dyneema ${ }^{\circledR}$ fibre rope with different steel surface and conditions. A comparative study [15] investigated the abrasion resistance of Polyester ropes and HMPE material used for Dyneema ${ }^{\circledR}$ ropes. It was found that the HMPE rope samples possessed a higher wear resistance, sustaining about three times as many cycles to failure as Polyester rope. As such, the test results for Dyneema ${ }^{\circledR}$ presented in the following are representative regarding the wear mechanism and will provide a conservative assessment of abrasion resistance 
Table 2

Set-up details

\begin{tabular}{|c|c|c|c|c|c|}
\hline & Test 1 & Test 2 & Test 3a & Test $3 b$ & Test 4 \\
\hline Steel guide & Panama fairlead & Corroded panama fairlead & \multicolumn{2}{|c|}{ Locked steel roller with Nylatron $^{\mathrm{TM}}$ liner } & $\begin{array}{l}\text { Unlocked steel roller } \\
\text { no liner }\end{array}$ \\
\hline $\mathrm{D} / \mathrm{d}$ & 11.6 & 11.6 & 10 & 10 & 10 \\
\hline Tested rope & \multicolumn{5}{|c|}{ Dyneema $^{\circledR} 32 \mathrm{~mm}$ diameter $738 \mathrm{kN} \mathrm{MBL}$} \\
\hline $\begin{array}{l}\text { Wrap angle of the rope } \\
\text { around the steel guide }\end{array}$ & $30^{\circ}$ & $30^{\circ}$ & $30^{\circ}$ & $30^{\circ}$ & $30^{\circ}$ \\
\hline Cycles & 1,500 & 1,500 & 1,500 & 500 & 1,500 \\
\hline Load cycles & \multicolumn{5}{|c|}{ Mean load $20 \% \mathrm{MBL}$, load range from 10 to $30 \% \mathrm{MBL}$} \\
\hline \multirow{2}{*}{$\begin{array}{l}\text { Surface finish RA }(\mu \mathrm{m}) \\
\text { before test }\end{array}$} & \multirow{2}{*}{128.5} & \multirow{2}{*}{254.3} & Along axis 7.6 & Along axis 17.8 & Along axis 21.8 \\
\hline & & & Perpendicular to axis 23.6 & Perpendicular to axis 71.1 & Perpendicular to axis 706.9 \\
\hline \multirow{2}{*}{ After test } & & & Along axis 17.8 & Along axis 17.8 & \\
\hline & & & Perpendicular to axis 71.1 & Perpendicular to axis 71.1 & \\
\hline
\end{tabular}

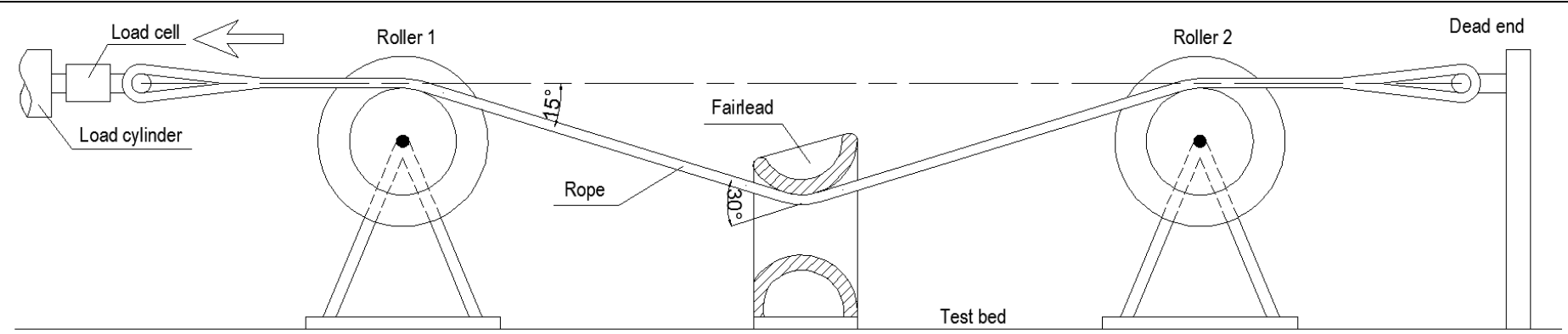

Figure 6. Hydraulic bench test - Steering cylinder on the left hand side, panama fairlead place between the two rollers, dead end on the right hand side

of polyester ropes against steel surfaces. The details of the experiment are given in Table 2.

All the tests described in this section have been conducted on dry rope samples at a 20 second period for 500 or 1,500 cycles.

The applied mean load was $20 \%$ of the MBL, with a load range from 10 to $30 \% \mathrm{MBL}$. The test program included two steel guide rollers to deflect the rope around the surface to be tested (either a panama fairlead or steel roller). In the centre of Figure 6 the panama fairlead is shown with the two steel guide rollers on each side.

A total of four rope samples were tested on this bench as described:

\begin{tabular}{l|l} 
Test 1 & A brand new panama fairlead (painted surface).
\end{tabular}

Test 2 The same panama fairlead with a chemical solution applied to initiate corrosion.

Test 3a, 3b A locked smooth steel roller with a $6 \mathrm{~mm}$ Nylatron ${ }^{\mathrm{TM}}$ wear pad.

Test 4

An unlocked smooth steel roller.

Prior to the second wear test, and after simulated corrosion pitting, surface roughness data were obtained on key wear surfaces using a Taylor Hobson Surtronic Duo Roughness Checker. The surface roughness parameter used is $\mathrm{Ra}$ (Roughness average), which is the most used international parameter of roughness. The average surface roughness was Ra $254.3 \mu \mathrm{m}$, as contrasted with a Ra of $128.5 \mu \mathrm{m}$ for Rope Test 1 . The surface roughness conditions for Test 2 were twice greater than for Test 1. The original surface shown in Figure 7 was prior to treatment with $10 \%$ hydrochloric acid in a cellulose emulsion was mostly bright reflective silver to grey with some patches of sand texture between what appeared to be grinding marks. Moderate surface appearance and colour change noted as shown by the macro-photograph in Figure 8 . The current appearance is dull dark grey with oxide brown staining and more generalised roughness to the touch. The test surface was neutralised with common baking soda and water then flushed with tap water prior to starting Rope Test 2. Surface roughness measurements were made for each test.

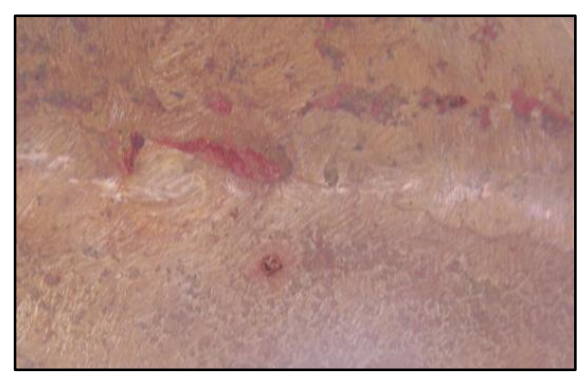

Figure 7. Fairlead un-corroded

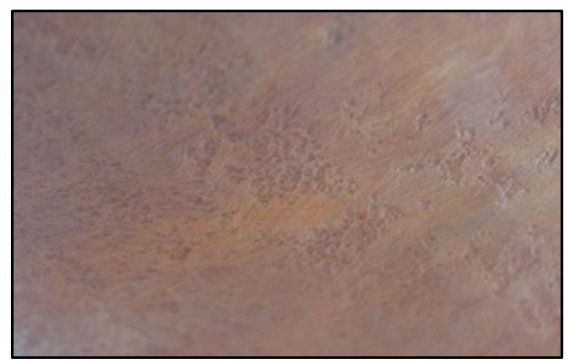

Figure 8. Fairlead corroded with spot marks

The load cell measuring the tension applied to the rope samples was calibrated before starting the tests. A $30^{\circ}$ wrap angle between the tested guides and the rollers was chosen, causing the wrap angle to be $15^{\circ}$ around the two rollers. This angle was chosen upon recommendations from the Oil Companies International Marine Forum [16] which does not recommend a vertical angle with the horizontal plane greater than $25^{\circ}$. 
Visual inspection results showing yarn conditions (ranging from no damage to broken yarn) for the different test regimes (test $1-4$ ) and locations (roller 2, steel guide, roller 1) used to calculate the rope residual strength.

\begin{tabular}{|c|c|c|c|c|c|c|c|c|c|c|c|c|c|c|c|c|}
\hline & \multicolumn{3}{|c|}{ Test 1} & \multicolumn{3}{|c|}{ Test 2} & \multicolumn{3}{|c|}{ Test $3 \mathrm{a}$} & \multicolumn{3}{|c|}{ Test $3 b$} & \multicolumn{3}{|c|}{ Test 4} \\
\hline & & 1 & guide & 2 & 1 & guide & 2 & 1 & guide & 2 & 1 & guide & 2 & 1 & guide & 2 \\
\hline \multirow{6}{*}{ 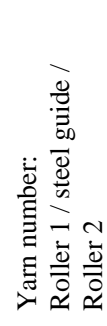 } & No damage & 78 & 54 & 53 & 105 & 5 & 86 & 92 & 105 & 82 & 94 & 82 & 100 & 72 & 69 & 58 \\
\hline & Flattened & 0 & 0 & 0 & 0 & 0 & 0 & 0 & 5 & 0 & 0 & 17 & 0 & 0 & 6 & 0 \\
\hline & Mild damage & 47 & 47 & 50 & 31 & 83 & 35 & 45 & 39 & 27 & 40 & 51 & 24 & 36 & 49 & 39 \\
\hline & Modest damage & 19 & 11 & 42 & 12 & 24 & 26 & 9 & 7 & 29 & 13 & 6 & 11 & 34 & 28 & 35 \\
\hline & Severe damage & 12 & 40 & 11 & 8 & 26 & 9 & 10 & 0 & 18 & 9 & 0 & 21 & 14 & 4 & 23 \\
\hline & Broken yarn & 0 & 4 & 0 & 0 & 18 & 0 & 0 & 0 & 0 & 0 & 0 & 0 & 0 & 0 & 1 \\
\hline \multicolumn{2}{|c|}{ Residual strength (\%) * } & 79.7 & 67.9 & 77.2 & 82.3 & 63.0 & 80.2 & 82.3 & 85.3 & 76.6 & 81.7 & 84.1 & 77.8 & 77.4 & 81.1 & 73.2 \\
\hline \multicolumn{2}{|c|}{ Residual strength $(\%) * *$} & & & & & & & & & & & & & & 77 & \\
\hline
\end{tabular}

* $\quad$ Calculated from the yarn category method

** Calculated from the individual tensile results on all strands

The main focus of the test program was to investigate the sensitivity of fairlead and roller materials to wear on Dyneema ${ }^{\circledR}$ fibre ropes under severe loading conditions. The research work assessed the loss of strength of abraded fibre ropes. The bench test shown in Figure 6 was designed for this purpose.

Table 3

Rope damage classification

\begin{tabular}{ll}
\hline Damage category & $\begin{array}{l}\text { Damage as percentage } \\
\text { of cross-sectional area (DM) }\end{array}$ \\
\hline No damage & 0 \\
$\begin{array}{l}\text { Compressed and } \\
\text { flattened }\end{array}$ & $\begin{array}{l}\text { Not applicable (no visual change in cross sectional } \\
\text { area) }\end{array}$ \\
Mild damage & $0<\mathrm{DM}<10$ \\
Modest damage & $10<\mathrm{DM}<50$ \\
Severe damage & $50<\mathrm{DM}<100$ \\
Failure & $\mathrm{DM}=100$ \\
\hline
\end{tabular}

\subsection{Methodology}

A methodology to estimate the residual strength of abraded rope is introduced in this section. Specific classification criteria were developed to perform visual inspection of the abraded fibre ropes. Such visual inspections aim to assess the percentage of residual strength of the abraded rope. The method consists first in a visual examination of each yarn constituting the rope.

The dissection of the fibre rope reveals the extent of the abrasion damage at the rope yarn level. These yarns were then categorised according to their nature of damage with an estimate of loss in cross sectional area. A classification comprising six damage categories is proposed in Table 3 . The proposed classification is subjective and care should be taken to acknowledge yarn compression to avoid incorrectly insinuating a loss of material.

Finally, a sufficient range of samples emanating from each category were tested to rupture to provide the yarn residual strength per category. The rope residual strength can then be calculated from the product of calibrated strength loss, numbers of yarns in each category and the realisation factor.

The residual strength was calculated using Eq. 3. The number of yarns that fell into each of the six categories of the classification were counted and then multiplied by the mean average MBL for each category.

$$
\left[\mathrm{RF} * \sum_{\text {category }=1}^{6}\left(\text { Yarn } * \text { YBLC }_{\text {category }}\right)\right] / \mathrm{MBL}_{\text {MEASURED }}
$$

Where:

YBLC $_{\text {category }}$ Yarn breaking load per category $(\mathrm{kN})$

The breaking test of one new rope sample demonstrated a MBL of $813 \mathrm{kN}$. Given that the sum of the yarn breaking loads of the fourth rope is $1,322 \mathrm{kN}$, RF was found to be 0.615 using Eq. 1 .

\subsection{Visual examination of the abraded rope samples}

The physical conditions of the rope samples were examined across their three points of contact with steel element. Early inspection indicated that a good range of abrasion damage was inflicted on the rope set.

Table 4 is populated by the number of yarns that fell in each damage category as defined in the methodology for the three contact areas as follows:

1. roller 1

2. steel guide to be tested

3. roller 2

During the two first tests, the damage was greatest at the steel guide contact. The opposite was found for the last three tests with the greatest damage occurring at the rollers.

On the second test five yarns were observed to be free of damage at the steel guide contact area. This is the lower number of un-damage yarns found during the test program.

A slight differential of damage was observed at the point of rope contact between the two rollers. The section of rope in contact with the roller nearest to the dead end side experienced less damage. This would be expected since the rope experiences lower load due to friction losses and lower axial stretch due to its shorter length.

A higher number of yarns were not damaged at the steel guide contact area for the three last tests. In the same way, severe damage was less for the three last tests.

Four and eighteen yarns were found to have failed on the first and second test respectively. No yarn failed when using a nylon 
wear pad and the roller. However, flattened yarns were observed at the steel guide contact area only.

The damage affecting the rope subjected to test $3 \mathrm{a}$ was marginally worse than test $3 \mathrm{~b}$. The same rope sample was used for tests $3 \mathrm{a}$ and $3 \mathrm{~b}$ with the ends reversed. This operation provided a new wear surface on the same rope and allowed the comparison between the wear after being subjected to 500 and 1,500 cycles. The extra 1,000 cycles applied to test $3 \mathrm{a}$ resulted in marginally greater damage. For these two tests, half of the rope yarns fell into the mild damage category, where damage was between 0 and $10 \%$ of the cross-sectional area.

It is noted that the steel guide did not rotate during the last test even though it was free to turn on a plain bearing.

\subsection{Yarn tensile tests}

The yarn tensile tests were conducted on 213 yarns originating from the four rope samples and the six damage categories. The sections of rope clear of the abrasion zone were also tested for the component rope yarn strengths. Results are listed in Table 5.

For the un-damaged rope test, the outer yarns are about $5 \%$ weaker than the inner yarns. The decline in tensile strength depending on the degree of abrasion varies from $87 \%$ to $29 \%$ residual strength. The variability of the results is very high for the severe damage at 59\%. However this variability is expected since this category contains damage to the yarn of between $50 \%$ and $100 \%$ cross sectional area.

Both compressed categories have suffered a loss of strength similar to mild damage. However the origin of the loss of strength is fibre deformation for the flattened yarn and abrasion for the mildly damaged yarn.

The yarns falling in each category were tested to the rupture to estimate the MBL. The mean average MBL was then identified for each damage category.

\subsection{Residual Strength}

From the results of the tensile tests, the residual strength of the four rope samples at each of the three points of contact was calculated with Eq. 3. Results are listed in the bottom part of Table 4. The residual strength of the section of the rope at roller 1 was always lower than the residual strength of the section at roller 2. At the section adjacent to roller 1, the motion of the rope was higher than the section in contact with roller 2. Also, the rope tension was higher at roller 1 on the steering cylinder side since this roller was the first of the three chafing points and does not benefit from friction loss over the steel guide.

Table 5

Results of the yarn tensile tests

\begin{tabular}{lllll}
\hline $\begin{array}{l}\text { Rope yarn } \\
\text { Damage category }\end{array}$ & $\begin{array}{l}\text { Breaking } \\
\text { load (N) }\end{array}$ & $\begin{array}{l}\text { Residual } \\
\text { strength (\%) }\end{array}$ & SD (N) & CoV (\%) \\
\hline $\begin{array}{l}\text { Un- Inner yarn } \\
\begin{array}{l}\text { abraded } \\
\text { yarn }\end{array}\end{array} \quad$ Outer yarn & 8255 & 102 & 287 & 3.3 \\
$\begin{array}{l}\text { Compressed and } \\
\text { flattened at surface of } \\
\text { abrasion zone }\end{array}$ & 6221 & 73 & 281 & 3.4 \\
$\begin{array}{l}\text { Compressed within } \\
\text { abrasion zone }\end{array}$ & 7410 & 87 & 659 & 13.8 \\
$\begin{array}{l}\text { Mild damage } \\
\text { Modest damage }\end{array}$ & 7128 & 84 & 793 & 11.1 \\
\begin{tabular}{l} 
Severe damage \\
\hline
\end{tabular} & 2453 & 29 & 939 & 16.1 \\
\hline
\end{tabular}

The residual strength for the new fairlead was higher compared with the residual strength of the corroded fairlead. The loss of strength due to the corrosion was found to be $5 \%$ of the residual strength when the surface roughness was varied from 128.5 to $254.3 \mu \mathrm{m}$.

This method has the advantage to estimate quickly the residual rope strength for a wide range of samples. The method was checked by breaking all the yarns of the fourth rope at the steel guide section. Good agreement was found between the two methods; the visual and category method estimated the residual strength of the rope at $81.1 \%$ whereas the tensile tests performed at this section estimated the residual strength at $77 \%$.

The test program has demonstrated that there is a linear relationship between the surface roughness of the steel element and the degradation of the rope residual strength.

\section{Failure analysis}

Numerical simulations were performed to replicate the commissioning conditions of the presented case study and aim to establish a robust tool to explain the failure of the polyester line.

\subsection{Numerical model}

Simulations were conducted using OrcaFlex ${ }^{\mathrm{TM}}$ (version 9.8a). This commercial software is a time-domain finite element solver that can predict the coupled response of a surface vessel or MRE device and its moorings. The Morison equation was applied to compute the forces on each segment of the mooring system.

The fundamental principle of this analysis was to establish the load history experienced by the polyester line during transit from the harbour to the commissioning site. The graphical rendered version of the system is shown in Figure 9.

\subsubsection{Input data}

Vessel dynamics: The vessel's Response Amplitude Operators (RAOs) data originate from ANSYS AQWA simulations for a simplified hull shape considering a mass of the vessel of 700 tonnes and a dimension of $26 \mathrm{~m}$ long, $9 \mathrm{~m}$ width and $2.5 \mathrm{~m}$ draught. RAOs were computed for a wave period ranging from 2 to 20 seconds, in increments of 0.06 seconds and for different wave directions ranging from 0 to $180^{\circ}$, in increments of $9^{\circ}$. The speed of the vessel was limited to 2.6 knots in order to reduce the swinging of the anchoring system.

Environmental data: During the operation, the sea conditions were recorded by a Fugro SEAWATCH Mini II wave buoy located 2 nautical miles away from the site. Prior to transit the wave buoy indicated a significant wave height $(\mathrm{Hs})$ equal to $1.00 \mathrm{~m}$ and a peak period (Tp) equal to $7 \mathrm{~s}$. The sea conditions subsequently worsened and reached a peak of $\mathrm{Hs}$ $=1.50 \mathrm{~m}$ one hour after the beginning of the transit. These wave conditions were replicated by a JONSWAP spectrum defined with a representative $\mathrm{Hs}$ and $\mathrm{Tp}$ value as recorded by the wave buoy. To enhance the stability of the model, the wave direction was assumed to be linear. The consideration of a wave directional spectrum would result in a small influence on the dynamic of the vessel especially at such low speed.

Anchor: The 28 tonnes anchoring system plays an important role in the dynamic loading. The added mass of the anchor was approximated from [17].

\subsubsection{Information available from the marine operation}

Observations relative to vessel's motion and polyester line's displacement made during the commissioning of the prototype 
were used to calibrate the numerical model. While $\mathrm{Hs}=1.25 \mathrm{~m}$, the following observations were made:

- The vessel rolling at $+/-5^{\circ}$ and insignificant pitching while encountering a $90^{\circ}$ head sea

- The vessel rolling at $+/-5^{\circ}$ and pitching at $+/-5^{\circ}$ while the encountering $55^{\circ}$ head sea

- The polyester line stretching by $+/-50 \mathrm{~mm}$ and occasionally sliding by $+/-40 \mathrm{~mm}$.

The motion of the vessel was found to be correctly replicated, thus no corrections on the vessel RAOs were introduced to the model.

However the line displacement (sliding and stretching) over the roller has been corrected with a sensitivity analysis which aimed to estimate and correct the friction forces experienced by the polyester rope on the steel roller. These friction forces were modelled through shear and normal stiffness parameters which determine the rate at which the force (prototype's weight) applied to an object (steel roller) increases with the area of contact and depth of penetration into the object. Several iterations were made until the line displacement matched the observations made.

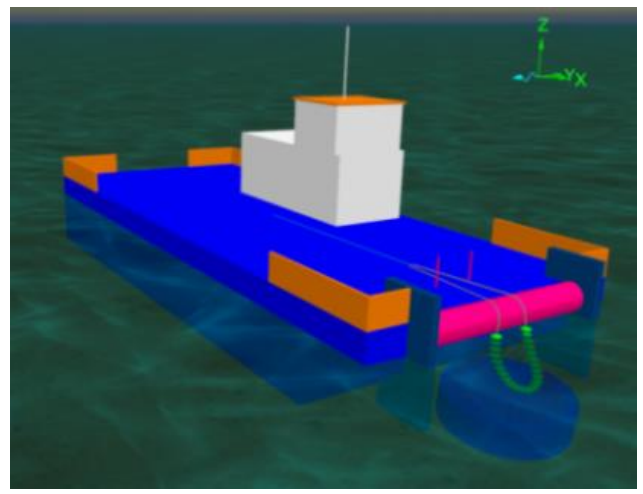

Figure 9. 3D view of the numerical modelling

\subsection{Modelling of a range of sea conditions}

The numerical model was used to investigate the influence of the sea conditions on the loading and sliding of the rope and determine the importance of abrasion sustained by the rope. The model was run over five different $\mathrm{Hs}$ values from $0.50 \mathrm{~m}$ up to $1.50 \mathrm{~m}$ individually. Results are shown in Figure 11 and are summarised in Table 6.

For the same significant wave height, the plots presented in Figure 11 show the significant influence of wave direction on the vessel response and lateral sliding of the rope. A sample of dataset of 400 seconds was chosen to facilitate the viewing of the results. As shown in plot $\mathrm{E}$ the lateral sliding of the roller is 2.5 times greater when the wave direction approached the vessel with a $55^{\circ}$ angle. The large dispersion of the signal for the lateral movement is an indicator of the occurrence of important friction forces on the rope.

Moreover these friction forces are combined with high peak loads resulting from an increase in pitch motion of the vessel as shown in plots $\mathrm{C}$ and $\mathrm{D}$.

Table 6 summarises the results of the six simulations. The mean load on the line is identical over all of the simulations (around 11\% MBL). This value corresponds to the submerged weight of the anchor. For a relatively calm sea $(\mathrm{Hs}=0.50 \mathrm{~m})$ it is noted that a small amount of rope sliding occurred (+/- $4 \mathrm{~mm})$, considerably smaller than the moderate sea simulation $(\mathrm{Hs}=$ $1.50 \mathrm{~m})$ where the sliding motion were found to be nearly 20 times greater $(+/-50 \mathrm{~mm})$. The same conclusion can be made for the axial stretching and load range experienced by the rope. For a value of Hs three times higher, the axial stretching was multiplied by twelve. In the same way the amplitude of the load range was found to be $2.5 \% \mathrm{MBL}$ for $\mathrm{Hs}=0.5 \mathrm{~m}$ and $10.5 \% \mathrm{MBL}$ for $\mathrm{Hs}=$ $1.5 \mathrm{~m}$.

Due to the short period wave induced motions, the rope was observed to slide occasionally by $+/-40 \mathrm{~mm}$ alongside the roller and to stretch by $+/-50 \mathrm{~mm}$ allowing back and forth rotation of the roller when $\mathrm{Hs}=1.50 \mathrm{~m}$. These observations reflect the results of the simulation for the same environmental conditions.

\subsection{Modelling of the load experienced by the polyester line during the transport}

The numerical model was then re-run to replicate the conditions as observed during the marine operations to generate the load history presented in Figure 10.

During transit the polyester rope mainly experienced low amplitude loads with intermittent higher amplitude load cycles for the first 5,000 seconds. During the last 400 seconds of the simulation, the load amplitude is up to three times larger. Some peak loads higher than $20 \% \mathrm{MBL}$ are visible. This short period of 400 seconds correspond with the moment where the vessel manoeuvred at the vicinity of the targeted site.

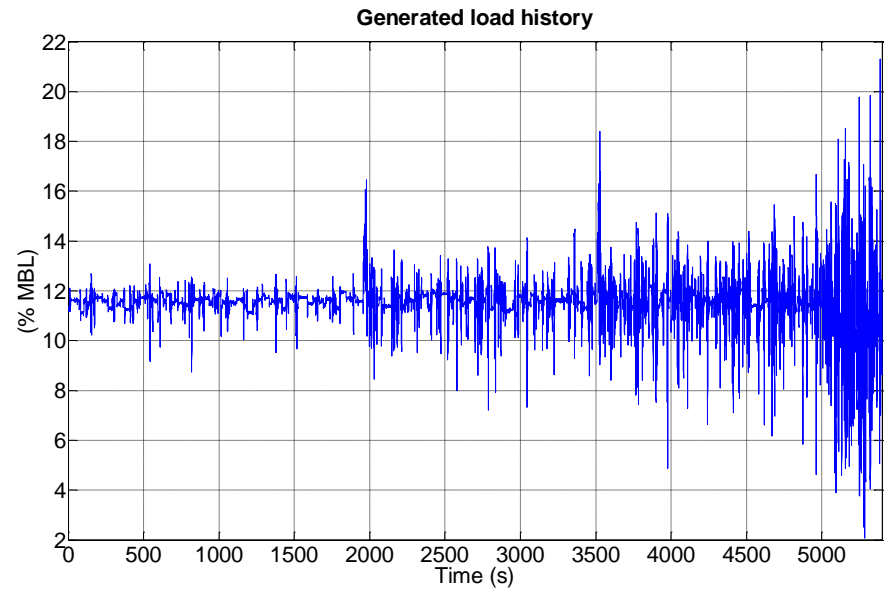

Figure 10. Load history of the polyester line for a 90 minute simulation representing the conditions up to failure

The methodology used to quantify the fatigue load during transit is similar to the method reported in [18]. The rainflow cycle counting method [19] was used to quantify the number of load cycles for different load range intervals. From this method, it is estimated that the polyester line experienced approximately 1,500 load cycles during the transit period. From the rainflow diagram presented in Figure 12, it can be observed that the mean tension range applied on the drawstring line was similar to the submerged weight of the anchor (11\% MBL). The red cells indicate that the rope was subjected to low amplitude load cycles $(10-12 \% \mathrm{MBL})$. However a scattered distribution of the load amplitude is visible around these red cells. It is an indicator of the occurrence of higher load amplitudes $(8-14 \% \mathrm{MBL})$. The load cycles in the upper left corner cells have the largest amplitudes and will thus result in the largest fatigue damage including the occurrence of occasional very large load amplitudes $(2-26 \%$ MBL). Due to the low number of cycles the rope has experienced and the outcomes of the SEM, it can be concluded that fatigue was not the governing failure cause.

The fatigue life for an undamaged rope can be estimated using Eq. 4 from [20]:

$$
\log _{10}(\mathrm{~N})=-\mathrm{M} \cdot \log _{10}(\mathrm{R})+\mathrm{k}
$$


Where:

$\mathrm{N} \quad$ Number of load cycles to failure

M Slope of the design T-N curve

$\mathrm{k} \quad$ Intercept of the design T-N curve intercept

$\mathrm{R} \quad$ Ratio of tension range to break strength

The significant load range applied to the rope during the transit period was found to be 5\%. Eq. 4 stems from fatigue life testing performed on higher load ranges, typically 40, 50, 60 and $70 \%$. Indeed due to a matter of cost, it is impossible to perform such low cycle fatigue tests on polyester rope. Tens of million cycles would be necessary to reach the fatigue life. For a load range lower than $40 \%$, the number of cycles to failure could be extrapolated linearly based on the higher load range test data. Moreover a second steeper curve is likely to be caused by internal wear at such a low load range. The use of Eq.4 to estimate the fatigue life of the fibre rope subjected to low load range may produce erroneous results.

Figure 13 shows the number of load cycles for each load range which would have been necessary to break the undamaged polyester rope. This graph is obtained by applying Eq. 4 to each load range for the polyester line's characteristics as given in section 3.1. This graph is unduly optimistic since the rope bearing capacity was decreasing over the time due to wear caused by abrasion.

Figure 14 is obtained by combination of Figure 12 and Figure 13. These four figures show the number of loads cycles for each load range emanating from the simulated load history to reach the failure. Figure 14 A represents the number of load cycles before failure at the early start of the operation, i.e. when the polyester line was new and un-abraded. The simulated load history would have not been important enough to cause the failure on the rope if un-abraded for the entire period of commissioning. The same conclusions can be drawn for a remaining rope strength capacity of $75 \%$ and $50 \%$ respectively shown in Figure $14 \mathrm{~B}$ and Figure $14 \mathrm{C}$.

However, in case of severe abrasion (i.e. with $25 \%$ remaining bearing capacity as shown in Figure $14 \mathrm{D}$ ) the load range will have increased up to the equivalent of $100 \%$ of the abraded rope's MBL. As forces have to be withstood by a reduced crosssection, it will have weakened the remaining rope before failure. As the abrasion mechanism is dynamic with time and loads, it is however difficult to quantify the exact fatigue contribution.

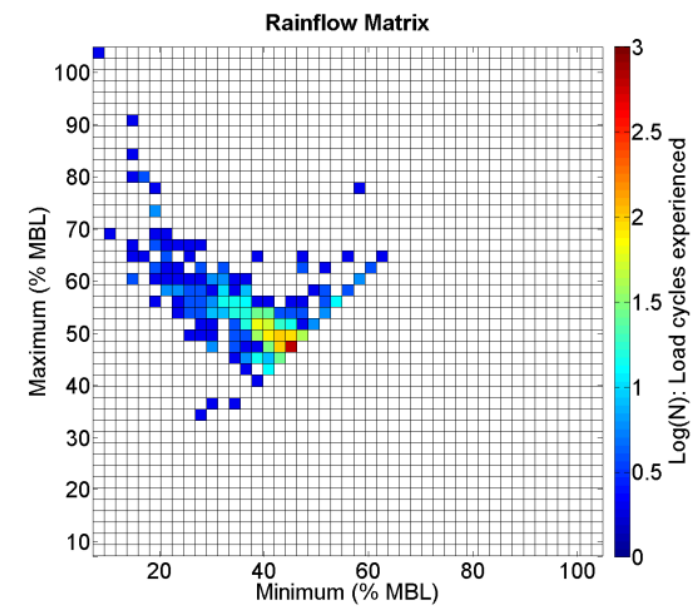

Figure 12. Rainflow matrix calculated from the simulated load history

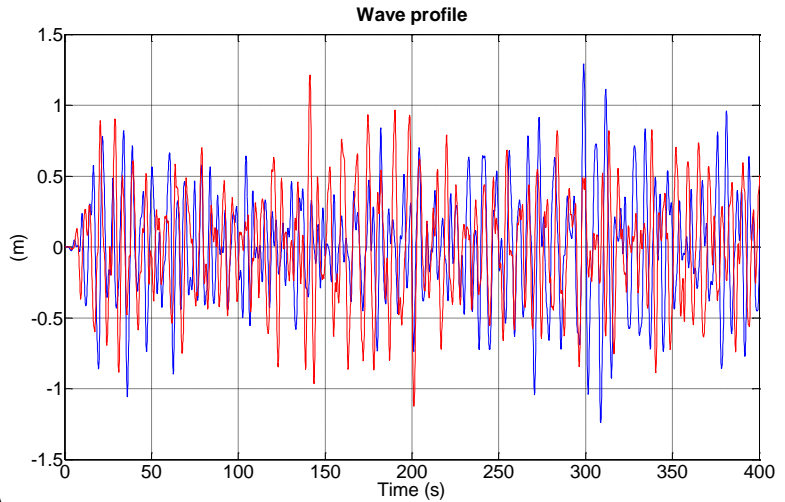

A

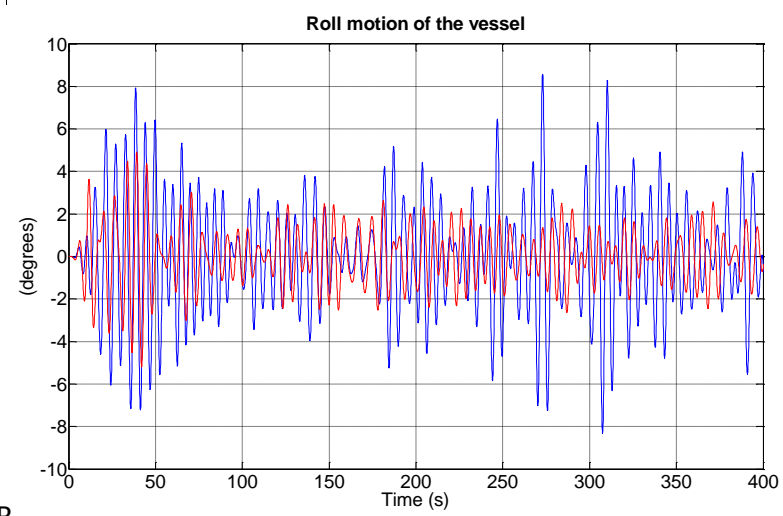

B

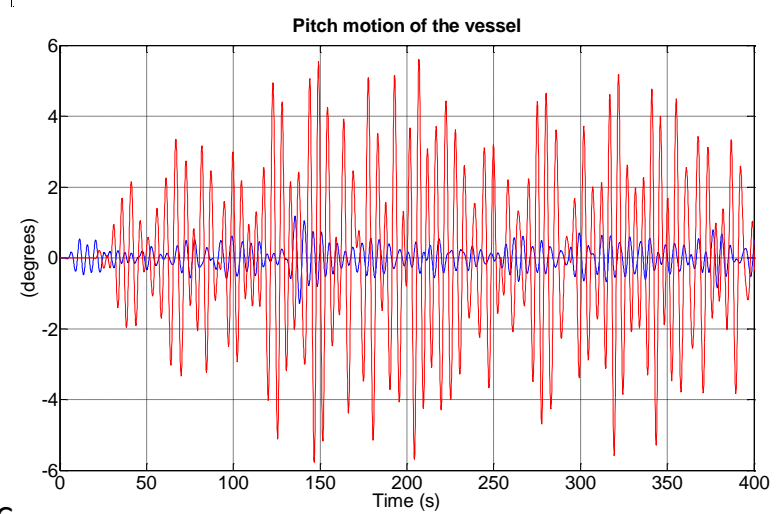

c
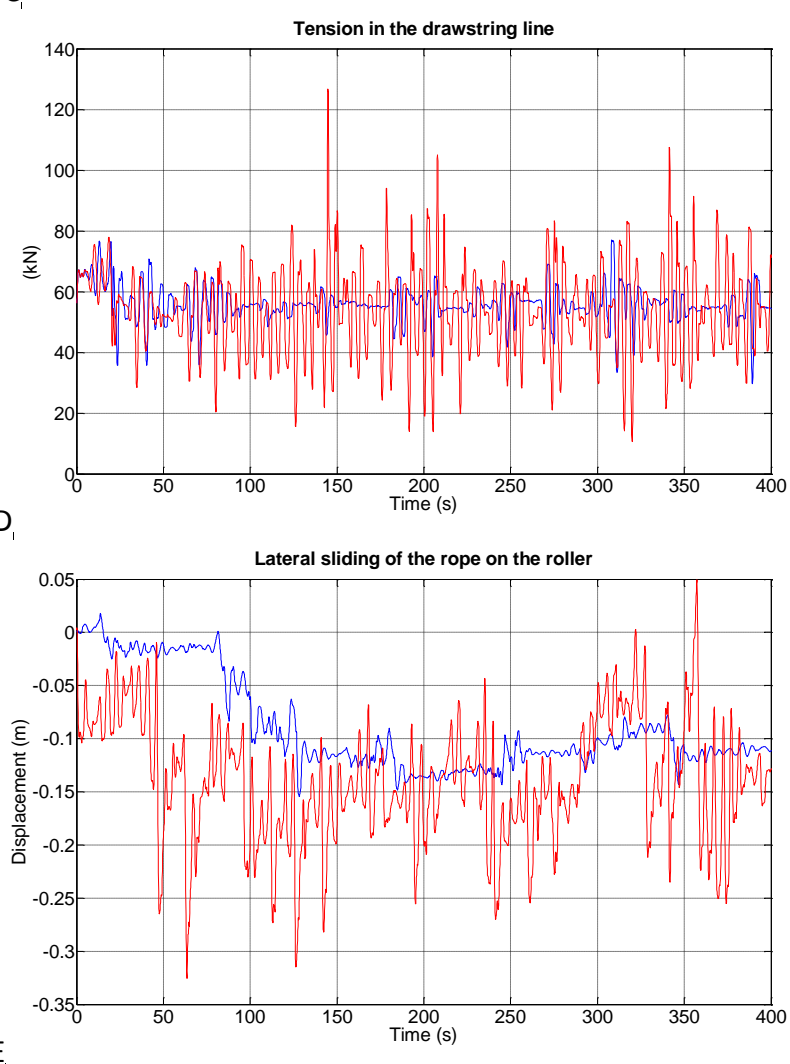

Figure 11. Comparison between two numerical model output $-\mathrm{Hs}=$ $1.5 \mathrm{~m} 90^{\circ}$ heading sea in blue and $\mathrm{Hs}=1.5 \mathrm{~m} 55^{\circ}$ heading sea in red 


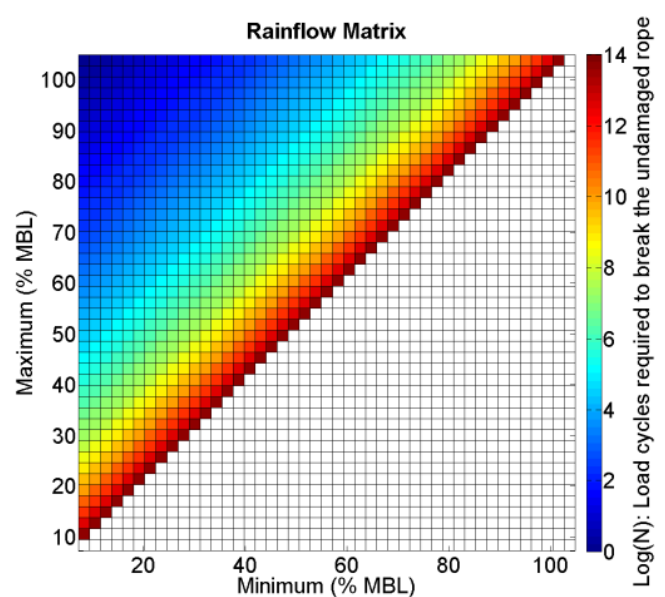

Figure 13. Rainflow matrix calculated from Eq. 4 showing the load cycles required to break the un-damaged polyester rope

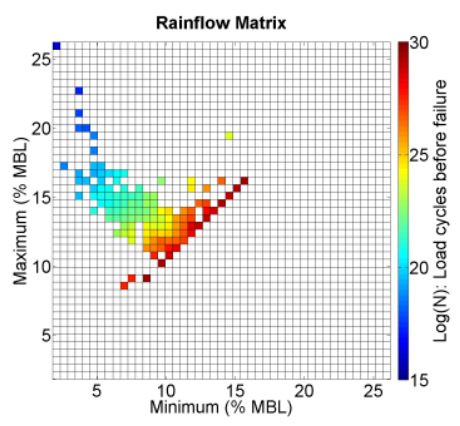

A. $100 \%$ Rope strength capacity

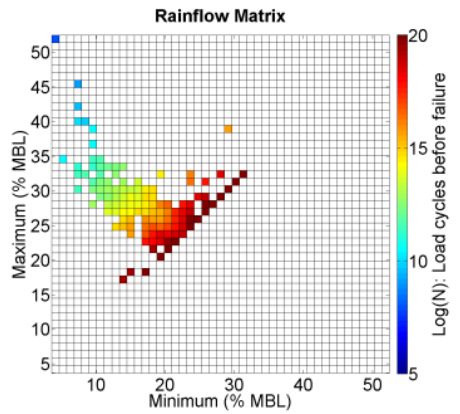

C. $50 \%$ Rope strength capacity

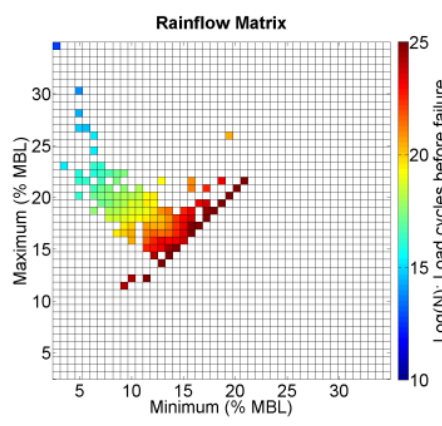

B. $75 \%$ Rope strength capacity

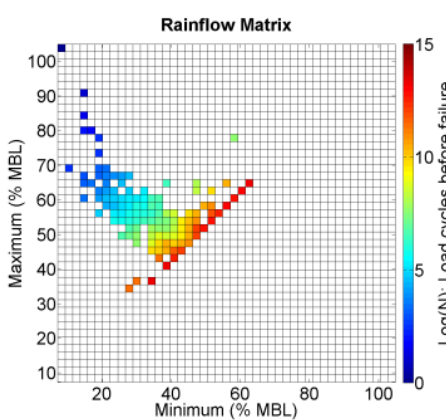

D. $25 \%$ Rope strength capacity
Figure 14. Rainflow matrix showing the number of load cycles before failure

\section{Discussion}

The abrasion of the polyester rope was supported by visual inspection, SEM, tensile tests and numerical model. The analysis has considered the properties of the rope, the steel roller surface and the applied loading conditions. The test and simulation results indicate that the roughness of the steel roller surface was the main cause of the abrasion damage sustained by the rope.
Rupture is likely to have been exacerbated by the dynamic motion of the vessel and suspended anchor, causing i) highly dynamic loading of the rope and ii) motion of the rope across the roller. The wear damage on the polyester line was severe; the effective area of the line was reduced by $60 \%$ ( 7 of 12 strands worn through) and the residual strength of the abraded section was found to be $14 \% \mathrm{MBL}$.

The laboratory tested Dyneema ${ }^{\circledR}$ rope samples were subjected to broadly similar loads and number of cycles as the polyester rope during the commissioning of the MRE device. At the end of the test, for a Dyneema ${ }^{\circledR}$ rope in contact with a rough steel element $(\operatorname{Ra} 254.3 \mu \mathrm{m})$, the residual strength is $63 \% \mathrm{MBL}$. After the field trial, the residual strength of the polyester rope was $14 \%$ MBL. It should be noted that the experimental test was performed on Dyneema ${ }^{\circledR}$ rope samples due to its better wear resistance compared to polyester rope. In both cases the reduction of the rope bearing capacity is serious and critical.

When the outer yarns of the rope were abraded, the reduction of the effective cross section of the rope led to an increase of loading and subsequent stress in the remaining strands. The direct consequence of this cross sectional area loss was a dynamic reduction of the residual strength of the line. As a result, the abrasion mechanism continued until the rope failed under loading.

Reduction of the rope bearing capacity during the commissioning and the test program

The effect of the surface finish of the steel guide on the percentage of residual strength is shown in Figure 15. A linear trend is visible demonstrating that a rougher surface finish will lead to higher rope damage and lower resultant residual strength. The second test used the roughest steel guide surface $(254.3 \mu \mathrm{m})$ and had thus resulted in the highest strength loss (38\%). In the same way, the smoothest steel guide surface $(7.6 \mu \mathrm{m})$ on the test 3 resulted in the lowest strength loss (15\%). These observations correspond proportionally with the number of damaged yarns in Table 4: The rope of the second test was reported to have the highest number of damaged yarns (151 damaged yarns) and the rope of the third test were reported to have the lowest number of damaged yarns (51 damaged yarns).

The abrasion tests detailed in this paper have shown that the wear damage was slightly different when the rope was subjected to an additional 1,000 load cycles. Table 7 shows that the difference in residual strength of the rope is $+/-1 \%$ when cycled for an extra 1,000 load cycles. It was then found that the abrasion phenomenon occurred predominantly at the beginning of the testing. Indeed the roughness of the roller was found to be lower after testing. This is because the rope is effectively polishing the surface of the steel during cycling. This correlates with Figure 2 in which clear marks of polished steel are observed on the roller where the line was located.

Table 6

Numerical model results

\begin{tabular}{llllllll}
\hline $\begin{array}{l}\text { Hs } \\
(\mathrm{m})\end{array}$ & $\begin{array}{l}\text { Mean load } \\
(\% \mathrm{MBL})\end{array}$ & $\begin{array}{l}\text { Load range } \\
(\% \mathrm{MBL})\end{array}$ & $\mathrm{SD}$ & $\begin{array}{l}\text { Lateral sliding } \\
(+/-\mathrm{mm})\end{array}$ & $\mathrm{SD}$ & $\begin{array}{c}\text { Axial stretching } \\
(+/-\mathrm{mm})\end{array}$ & $\mathrm{SD}$ \\
\hline 0.50 & 11 & $11-13.4$ & 2.11 & 4 & 0.0019 & 2 & 0.0017 \\
0.75 & 11 & $11-13.5$ & 2.40 & 6 & 0.0077 & 5 & 0.0028 \\
1.00 & 11 & $10.3-13.7$ & 3.06 & 10 & 0.0192 & 12 & 0.0049 \\
1.25 & 11 & $9.6-14.1$ & 4.25 & 22 & 0.0503 & 20 & 0.0085 \\
1.50 & 11 & $8.8-14.7$ & 5.90 & 50 & 0.0867 & 31 & 0.0132 \\
$1.50+55^{\circ}$ head sea & 11 & $5-17.9$ & 14.60 & 134 & 0.3761 & 112 & 0.2580 \\
\hline
\end{tabular}




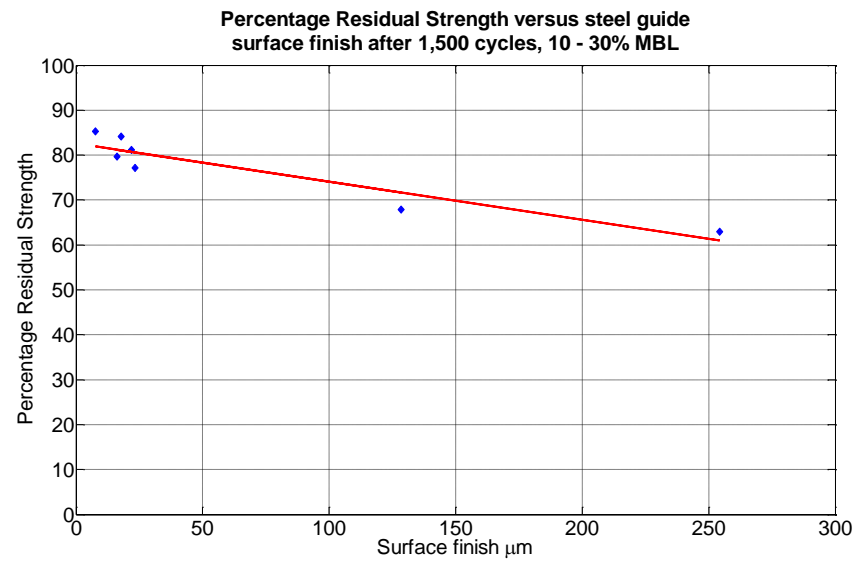

Figure 15. Strength loss against surface roughness (values listed in Table 2 and Table 4)

Table 7

Residual strength difference with an extra 1,000 cycles

\begin{tabular}{lccc}
\hline \multirow{2}{*}{ Abrasion region } & \multicolumn{2}{c}{$\%$ Residual strength } & \multirow{2}{*}{ Difference (\%) } \\
& 500 cycles & 1,500 cycles & \\
\hline Roller 1 & 76.6 & 77.8 & -1.2 \\
Lined roller fairlead & 85.3 & 84.1 & 1.2 \\
Roller 2 & 81.7 & 81.7 & 0 \\
\hline
\end{tabular}

Existing results on residual strength estimation of damaged fibre rope

A relation between strength loss and rope cross sectional area loss was found in Ref. [21]; for a 12-strand polyester rope with a $40 \%$ damaged area the strength loss calculated with the Eq. 5.

Residual Strength $=1-(1.6-2 *$ cross sectional area loss $)$

Considering a cross sectional area loss of $58 \%$ corresponding to seven failed strands, the residual strength is found to be $56 \%$. However this equation originates from tests performed on rope with artificial damage and thus does not consider abrasion damage. This paper has shown that abrasion damage can reduce the residual strength to $14 \% \mathrm{MBL}$. The reason for the difference is the nature of the damage, in the artificial damage tests the damage was discrete whereas in the MRE polyester line failure the damage was spread evenly over one whole pitch length (and beyond).

\section{Need to conduct simulations of the commissioning phase design}

Considering the case of significant pitch motions of the vessel $\left(+/-5^{\circ}\right)$ induced by waves of $\mathrm{Hs}=1.50 \mathrm{~m}$ facing the vessel at $55^{\circ}$, it was found that the load amplitude in the polyester line can be up to $26 \%$ MBL. The residual strength of the rope at this section was estimated to be $14 \% \mathrm{MBL}$ at the time of failure. The simulation therefore strongly indicates that large amplitude dynamic loading initiated rupture of the rope once it was severely abraded due to sliding over the roller.

\section{Conclusion}

The reported case study in this paper is the first instance of the breaking of a polyester mooring line used as fastening during transit and commissioning of a MRE device. This publication aims to help MRE developers to avoid issues with fibre rope abrasion during the commissioning of their devices.

From the joint expertise of TTI and the UoE, the loss in residual strength of a fibre rope submitted to abrasion was evaluated. Outputs obtained from the modelling, the wear tests and SEM provide insight into the significance and influence of abrasion damage on rope load bearing capacity and fatigue life.

It was found that even very small amounts of surface roughness on the bearing item can significantly fracture the yarns thus reducing the residual strength of the rope.

Also the abrasion effect occurs at the beginning of the load cycles, after-which the steel surface was polished by the rope at the expense of the outer load bearing elements of the rope.

Based on the results of this study it is concluded that the surface roughness of contacting steel elements should be less than $\mathrm{Ra} 10$ to avoid causing significant damage to fibre ropes.

Attention should be given to the nature of the material in contact with the fibre line. This paper recommends the use of lubricated nylon pad to limit abrasive wear. It should be noted that even if carbon steel or stainless steel surface is polished, pitting corrosion can forms very quickly after short exposure to marine environment and so this material has to be maintained very often which may be impractical. All surface types lead to some plastic deformation of the fibre and result in a limited loss of the strength which must be included in the safety factor for calculating the required rope strength. For example DNV [22] specifies a minimum safety factor of 1.65 for polyester, 2.0 for HMPE and aramid and 2.5 for all other fibre materials to allow for uncertainties in material properties, wear, etc.

A numerical model can predict the loading regimes experienced by the line for a given sea states at the design phase. Also the modelling has demonstrated the importance of considering load cases resulting not only from transit but also manoeuvring operations while at the target site when the wave direction generates an important dynamic motion of the vessel. While the Hs value was three times higher, the axial stretching of the line was multiplied by twelve. Therefore this paper recommends to carrying out a thorough numerical modelling of the MRE prototype being transited and commissioned to the site.

This paper has also shown the significant sea conditions that influence the sliding and stretching of lines which could result in quick and severe abrasion damage with a subsequent significant reduction of the line residual strength.

By using suitable methods and appropriate fairleads to handle fibre mooring lines, the transit and commissioning of MRE devices can be made safer, with the risk of failure occurring reduced.

\section{Further work}

There is not yet sufficient information on the nature, extent and rate of polyester rope deterioration mechanisms due to external abrasion over fairleads or rollers. This paper has demonstrated that the abrasion effects between fibre ropes and steel guides can be extremely critical and could lead to rupture. There is sufficient information in this paper to justify further investigation on the abrasion mechanism occurring at the interface between the steel guide and fibre rope.

It has been demonstrated through testing that abrasion can result in a significant reduction of the MBL of the rope $(86 \%$ reduction in the case study presented in this paper). The characterisation of the MBL reduction rate needs to be investigated in order to inform component lifetime predictions.

The abrasion tests have investigated the axial sliding of the fibre rope along the steel guide. However the effect of combined axial and lateral sliding on the loading of individual rope elements has yet to be quantified. 


\section{Acknowledgements}

The authors would like to acknowledge the support Marine Renewables Commercialisation Fund (MRCF) administrated by the Carbon Trust under the Array Technology Innovation Programme, for the project "Testing, Qualification and commercialisation of advanced mooring system for wave and tidal arrays". We also thank the examination and testing work conducted by Barry Windfield at TTI Testing Ltd, Bridon for supplying ropes, TenCate for bags, Vryhof Engineering for anchor design, Bluewater and DNV for qualification support.

This research has also received support from TTI Testing research and experimental testing over various projects investigating rope abrasion damage mechanisms.

\section{References}

[1] International Organization for Standardization, ISO 18692, Fibre ropes for offshore stationkeeping - Polyester, 2007.

[2] Lloyds's List, Marine equipment buyer's guide, 2010.

[3] US Navy Fiber Rope Design Practises and Criteria Manual, S6450-AA-MMO-010.

[4] Det Norske Veritas, "Section 4 - Mooring Equipment," in Offshore Standard - Position Mooring, 2013.

[5] S. D. Weller, L. Johanning, P. Davies and S. J. Banfield, "Synthetic mooring ropes for marine renewable energy applications" Renewable Energy, vol. 83, pp. 1268 - 1278, 2015.

[6] S. J. Banfield, N. F. Casey and R. Nataraja, "Durability of polyester deepwater mooring rope" Offshore technology conference, 2005.

[7] International Organization for Standardization, ISO 199017, Petroleum and natural gas industries - Specific requirements for offshore structures - Part 7: Stationkeeping systems for floating offshore structures and mobile offshore units, 2013.

[8] DNV-OS-E301, Position Mooring, 2013.

[9] K. Volpenhein and R. Chou, "Abrasion and twist effects on high-performance synthetic ropes for towing applications".
[10] Cordage Institute, "Cordage Institute Test Method CI$1503 "$.

[11] ASTM International, Standard Test Method for Wet and Dry Yarn-on-Yarn Abrasion Resistance, 2007.

[12] J. W. Hearle, "Chapter 24," in Atlas of Fibre Fracture and Damage to Textiles, 1998, pp. 192 - 202.

[13] H. A. McKenna, J. W. Hearle and N. O'Hear, Handbook of fibre rope technology, 2004.

[14] International Organization for Standardization, "ISO 2307, Fibre ropes - Determination of certain physical and mechanical properties" 2010.

[15] M. Pereira and F. Chimisso, "Synthetic ropes jackets made of polyester and high modulus polyethylene (HMPE): comparison of abrasion wearing behavior" 2010.

[16] Oil Companies International Marine Forum, "Mooring Equipment Guidelines MEG3 Third edition" in Witherby Publishing ISBN9781905331321, 2008.

[17] DNV-RP-C205, Environmental conditions and environmental loads, 2010.

[18] P. R. Thies, L. Johanning, V. Harnois, H. C. Smith and D. N. Parish, "Mooring line fatigue damage evaluation for floating marine energy" Renewable Energy, vol. 63, pp. 133-144, 2014

[19] I. Rychlik, A new definition of the rainflow cycle counting method, International Journal of Fatigue, vol. 9, issue 2, pp. 119-121, April 1987.

[20] S. Banfield, T. Versavel, R. Snell and R. Ahilan, Fatigue Curves for Polyester Moorings - A state-of-the-art review, Proc. Offshore Technology Conference, Paper Nr. OTC 12175, 2000.

[21] J. Flory, "Assessing strength loss of abraded and damaged fiber rope" IEEE, 2008.

[22] DNV-OS-H102, Marine Operations, Design and Fabrication, 2012.

[23] M. P. Vlasblom, J. Boesten, S. Leite and P. Davies, "Development of HMPE Fiber for Permanent Deepwater Offshore Mooring" in Offshore Technology Conference, Texas, 2012. 